\title{
LETTER
}

\section{A Response to "The Relationship Between Sleep and Quality of Life in Type 1 Diabetes Patients"}

Kirsten Nørgaard (D) · Urd Kielgast

Received: April 1, 2019 / Published online: April 26, 2019

(C) The Author(s) 2019

Keywords: Sleep disorders; Sleep quality; Type 1 diabetes

\section{Dear Editor,}

We thank you for the opportunity to respond to the kind and interesting letter from Dr. Monica Andersen, Universidade Federal de Sao Paulo, Brazil, regarding our recent publication in your journal.

We completely acknowledge that it is important to consider sleep quality and sleep disorders when evaluating life quality, especially in people with diabetes. We are also aware that the complex mechanisms of sleep are influenced by many factors, for example pain, and so it is possible that sleep disturbances may be one of the mechanisms behind our finding of

Enhanced Digital Features To view enhanced digital features for this article go to https://doi.org/10.6084/ m9.figshare.7951244.

K. Nørgaard ( $\bowtie) \cdot$ U. Kielgast

Copenhagen University Hospital Hvidovre,

Hvidovre, Denmark

e-mail: Kirsten.noergaard@regionh.dk

K. Nørgaard

Steno Diabetes Center Copenhagen, Gentofte,

Denmark

U. Kielgast

Zealand University Hospital, Køge, Denmark reduced quality of life in patients with rheumatological manifestations.

However, we did not investigate the mechanisms behind this reduced quality of life in our study, and we did not include questions regarding sleep quality in our already comprehensive questionnaire. Nevertheless, we do believe the topic to be highly relevant, and we will consider including an evaluation of sleep disturbances in future studies of life quality in type 1 diabetic patients in order to uncover the mechanisms behind this reduced quality of life. Such knowledge could then be used to improve the quality of life of type 1 diabetic patients.

Sincerely yours,

Kirsten Nørgaard and Urd Kielgast

\section{ACKNOWLEDGEMENTS}

Funding. No funding or sponsorship was received for this letter or its publication.

Authorship. All named authors meet the International Committee of Medical Journal Editors (ICMJE) criteria for authorship for this article, take responsibility for the integrity of the work as a whole, and have given their approval for this version to be published. 
Disclosures. Kirsten Nørgaard and Urd Kielgast have nothing to disclose.

Compliance with Ethics Guidelines. This letter is a response to a previously conducted study and does not contain any studies with human participants or animals performed by any of the authors.

Data Availability. Data sharing is not applicable to this article as no datasets were generated or analyzed during the current study.
Open Access. This article is distributed under the terms of the Creative Commons Attribution-NonCommercial 4.0 International License (http://creativecommons.org/licenses/ by-nc/4.0/), which permits any noncommercial use, distribution, and reproduction in any medium, provided you give appropriate credit to the original author(s) and the source, provide a link to the Creative Commons license, and indicate if changes were made. 